IP Periodica Polytechnica Transportation Engineering

46(1), pp. 1-10, 2018

https://doi.org/10.3311/PPtr.10605

Creative Commons Attribution (i)

RESEARCH ARTICLE

\section{Linear Mathematical Model for State- Space Representation of Small Scale Turbojet Engine with Variable Exhaust Nozzle}

\author{
Károly Beneda $^{1 *}$, Rudolf Andoga ${ }^{2}$, Ladislav Főzö ${ }^{3}$
}

Received 02 November 2016; accepted 30 January 2017

\begin{abstract}
The goal of this article is to develop a linear mathematical model for a small scale turbojet engine with variable convergent nozzle, and validate it on existing laboratory hardware owned by the authors' Departments.

Control of gas turbine engines plays an essential role in the safety of aviation. Although its role is constantly expanding, ranging from pilot workload reduction to detailed diagnostics, the basic competence is to regulate the thrust output of the power plant with maximum available accuracy, rapidity, stability, and robustness. The linear quadratic control is one possible solution for the above mentioned criteria.

Although civil aircraft engines include fixed exhaust nozzle geometry, in military applications the exhaust nozzle geometry is also adjustable to reach optimum efficiency due to better matching of individual engine components, etc.

In the present article the authors deduce the members of state space governing equations to acquire the basis of the $L Q$ control.

The established model is based on the physical laws describing the operational behavior of the engine as well as its complexity should be reduced to an acceptable level where still enough details remain to reflect the nature of the controlled object.
\end{abstract}

\section{Keywords}

turbojet engine, optimal control, LQR, state-space model, MATLAB Simulink, variable convergent exhaust nozzle, MIMO control

\footnotetext{
${ }^{1}$ Department of Aeronautics, Naval Architecture and Railway Vehicles, Faculty of Transport Engineering, Budapest University of Technology and Economics, H-1521 Budapest, P.O.B. 91, Hungary

${ }^{2}$ Department of Aviation Engineering, Faculty of Aeronautics, Technical University of Košice, 04121 Košice, Rampová 7, Slovakia

${ }^{3}$ Department of Aviation Engineering, Faculty of Aeronautics, Technical University of Košice, 04121 Košice, Rampová 7, Slovakia
}

Károly Beneda Researcher ID: H-4946-2016

Rudolf Andoga Researcher ID: H-5018-2016

Ladislav Főző Researcher ID: H-5026-2016

*Corresponding author, e-mail: kbeneda@vrht.bme.hu

\section{Introduction}

Gas turbines play an important role in transportation, especially in aviation, where the largest percentage of commercial and military aircraft implements a power plant including one of the three major applications, as turbojet, turbofan or turboprop engine.

Due to their favourable propulsive efficiency and relatively large operational range of flight velocities (Mach numbers), the different (low or high bypass ratio) turbofan engines propel a large variety of passenger and freighter aircraft in the civil aviation as well as combat airplanes (e.g. Zare and Veress, 2013). When the maximum speed of flight is reduced, the turboprop configuration assures the highest efficiency; its limits are constantly pushed towards the decreasing power output, as reported by Bicsák and Veress (2015).

Turbojet engines have a small, but not negligible share. They still can find their field of applications, like unmanned aerial vehicles developed for high altitudes and Mach numbers as shown by Verstraete et al. (2010) or Turan (2012); they can serve as auxiliary power plant for sailplanes or even for large aircraft, which has been detailed by Katolicky, Busov and Bartlova (2014) and Rohács J. and Rohács D. (2012); radio controlled models with micro turbojet engines are also very popular among hobbyists as reported by e.g. Matsunuma et al. (2005). This size is particularly suitable for university research, as it provides low cost operation while introduces the students into the real problems of turbine engine practice as shown by Pečinka and Jílek (2012) or Pásztor and Beneda (2015). The basic gas generator of such engine can be used in electrical power generation focused in Hamza (2013) or Nagahara et al. (2012); or can serve as backup power supply of fire fighting equipment as found in Nascimento et al. (2013). Fig. 1 shows the main important aero-thermal stations of the gas turbine engine used for development of the control and subsequent validation. Note the variable convergent exhaust nozzle especially suitable for the present research, which is present at both facilities detailed in Andoga, Komjáty, Főző and Madarász (2014) and Beneda (2008). 


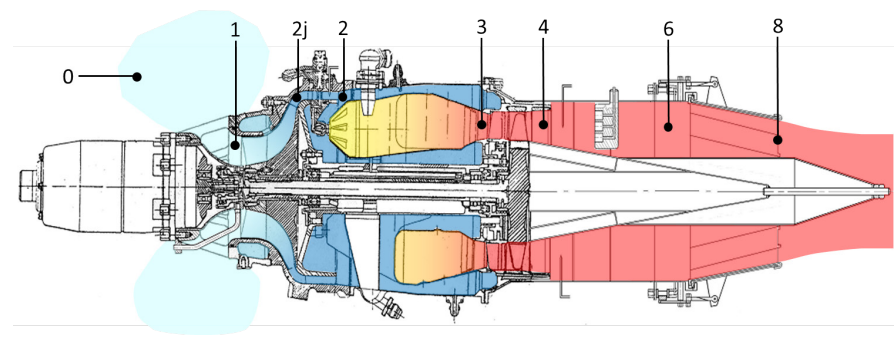

Fig. 1 Aerodynamic stations of the gas turbine engine TKT-1 (iSTC-21v similar)

The main goal of this research is to develop a mathematical model, which can be the basis of an optimal control system, and diagnostic system; relying on the previous experiments and developments of the authors like Andoga, Főzö, Madarász and Karol' (2013), emphasizing the implementation of a variable convergent exhaust nozzle. The results can be used in a variety of the above mentioned applications, primarily validated by those turbojet engine test benches: TKT-1 at Budapest and iSTC-21v at Košice.

\section{Developing the state-space model of turbojet engine}

\subsection{State-space representation}

The goal of this chapter is to represent the state-space model of the turbojet engine, with significant constraints applied to the real object, in order to allow less difficult approach of the control, as proposed by Wiese, Blom, Manzie, Brear and Kitchener (2015).

Primarily, one must understand the highly nonlinear behaviour of these plants, which is neglected in the present study, by selecting a single operational circumstance, around which the control system will be designed. Here we chose the approach of physical laws describing the behaviour of the system, instead of the black-box identification procedure which is also a common solution for modelling gas turbine engines (see Tavakolpour-Saleh et al. (2015)).

According to Williams and Lawrence (2007) the general nonlinear, time-varying state equation can be written as

$$
\begin{aligned}
& \dot{x}(t)=f[x(t), u(t), t] \\
& y(t)=h[x(t), u(t), t]
\end{aligned}
$$

In (1), $x$ represents the state vector of the plant, $u$ is the control vector, $y$ is the vector for the outputs, $f$ and $h$ are time-dependent nonlinear functions, $t$ is time. From the representation displayed in (1), in this paper we develop a linearized model with simplifying as the gas turbine is considered as a time-invariable system, although in reality some deterioration (e.g. turbine blade wear) will clearly result of system parameters to deviate from their nominal conditions.

For the linear quadratic control, what is the final goal of our investigations in the future, we must obtain the linearized version of the turbojet mathematical model.
For this reason, one must change to the deviation form of the main state space representation, substituting small changes in the variables instead of their absolute values. Let us introduce the deviation of the state and input variables as shown in Eq. (2), where the " 0 " indices show the value of the variables at a selected operation regime, while the symbols without notation represent the changed values.

$$
\tilde{x}=x-x_{0} ; \quad \tilde{u}=u-u_{0} ; \quad \tilde{y}=y-y_{0}
$$

Based on the proof by Williams and Lawrence (2007), one can substitute the nonlinear functions $f[x(t), u(t), t]$ and $h[x(t)$, $u(t), t]$ of (1) with their multivariable Taylor series around the selected operational point described by $\left[x_{0}(t), u_{0}(t), t\right]$. Supposing the state, input and output all remain in the vicinity of their respective nominal values the higher order terms in the Taylor series can be neglected, resulting in the following form, representing two matrix equations describing the change of the states and the correlation between states and outputs of the plant.

$$
\begin{aligned}
\dot{\tilde{x}}(t) & =\mathbf{A} \tilde{x}(t)+\mathbf{B} \tilde{u}(t) \\
\tilde{y}(t) & =\mathbf{C} \tilde{x}(t)+\mathbf{D} \tilde{u}(t)
\end{aligned}
$$

In Eq. (3) $\mathbf{A}, \mathbf{B}, \mathbf{C}$ and $\mathbf{D}$ stand for the system, input and output matrices, which contain the first partial derivatives as follows:

$$
\begin{array}{ll}
\mathbf{A}=\frac{\partial f[\tilde{x}(t), \tilde{u}(t)]}{\partial x} ; & \mathbf{B}=\frac{\partial f[\tilde{x}(t), \tilde{u}(t)]}{\partial u} \\
\mathbf{C}=\frac{\partial h[\tilde{x}(t), \tilde{u}(t)]}{\partial x} ; & \mathbf{D}=\frac{\partial h[\tilde{x}(t), \tilde{u}(t)]}{\partial u}
\end{array}
$$

The dimensions of the matrices are unknown yet, so we must specify the state input and output variables.

To identify state variables, one must describe the dynamic behaviour of the plant. As a single-shaft turbojet engine is inspected, reflecting on Fig. 1, one can identify two major mass and internal (heat) energy accumulators along with a single possibility of mechanical energy storage. These are namely the combustion chamber and the diffuser downstream of the turbine, and the rotor itself. Summarizing the above thoughts, the state vector contains the rotor speed $n$, total pressures and temperatures from turbine inlet $p_{3}{ }^{*} T_{3}{ }^{*}$ and nozzle inlet $p_{6}{ }^{*} T_{6}{ }^{*}$, according to Kulikov and Thompson (2004):

$$
x=\left[\begin{array}{lllll}
n & p_{3}^{*} & T_{3}^{*} & p_{6}^{*} & T_{6}^{*}
\end{array}\right]^{T}
$$

The input vector is consisting of two members, the conventional fuel mass flow rate $\dot{m}_{f u e l}$, which is practically the basis of any gas turbine engine control; and the area of exhaust nozzle $A_{8}$ :

$$
u=\left[\dot{m}_{\text {fuel }} A_{8}\right]^{T}
$$

The output vector is the collection of those variables, which are important for the control of the engine. For two input variables, the engine also has two parameters that can be controlled. Traditionally, rotor speed and engine pressure 
ratio (EPR) describe the thrust output, therefore these are used conventionally as output variables, as reported by Garg (1989).

$$
y=\left[\begin{array}{ll}
n & E P R
\end{array}\right]^{T}
$$

\subsection{Assumptions for the model}

As our final goal is to implement a LQ optimal control for the turbojet engine, several assumptions have to be made simplifying the model.

Generally, we have to assume constant physical and chemical properties of the working medium in each main component of the engine, i.e. specific gas constant, adiabatic exponent, isobaric and isochoric specific heats.

Heat loss by transmission, conduction or radiation from the gas turbine is neglected, as we also neglect the mass and internal energy storage in the passages of the compressor and turbine. For the various parts of the engine, constant pressure loss coefficients are taken into account, as their change is not significant throughout the operating envelope.

In many approaches like Tudosie (2012), there are simplified models, which present a more rapid development for control but lacks the physical realization of the plant therefore they cannot be used in diagnostics. Our model should retain all physical properties of the plant, as the further goal in this research is the development of a diagnostic system as well.

\subsection{Governing equations of the state-space representation}

The five members of the state vector represent the storage capability of the turbojet engine: rotor speed $n$ stands for mechanical energy, pressure and temperature values describe heat energy and mass storage. This also means that one must obtain the corresponding balance equations to describe the dynamic behavior of the plant.

According to Kulikov and Thompson (2004) the rotor speed derivative can be calculated as the difference between $P_{T}$ turbine power and $P_{C}$ compressor power as follows, supposing rotor speed $n$ is given as revolutions per minute (RPM):

$$
\dot{n}=\frac{P_{T} \eta_{m}-P_{C}}{\Theta(\pi / 30)^{2} n}
$$

where $\Theta \quad$ is the rotating inertia of the rotor; $\eta_{m} \quad$ is the mechanical efficiency of the engine.

The total pressure $p_{3}{ }^{*}$ and temperature $T_{3}{ }^{*}$ upstream of the turbine can be considered as average values at the combustion chamber exit as suggested by Ailer, Sánta, Szederkényi and Hangos (2001). They represent the ability of the combustion chamber to conserve mass and internal energy of the flow.

The derivative of turbine inlet total pressure can be expressed from the ideal gas law, taking into account that the specific gas constant $R_{g}$ and combustion chamber volume $V_{C C}$ are constant, only changes in the mass contained in the combustion chamber $\left(m_{C C}\right)$ and turbine inlet temperature $T_{3}^{*}$ will have an effect:

$$
\begin{gathered}
p_{3}^{*}=\frac{m_{C C} R_{g} T_{3}^{*}}{V_{C C}} \rightarrow \dot{p}_{3}^{*}=\frac{d}{d t}\left(\frac{m_{C C} R_{g} T_{3}^{*}}{V_{C C}}\right)= \\
=\frac{m_{C C} R_{g} \dot{T}_{3}^{*}}{V_{C C}}+\frac{\frac{d m_{C C}}{d t} R_{g} T_{3}^{*}}{V_{C C}} \\
\dot{p}_{3}^{*}=\frac{p_{3}^{*} \dot{T}_{3}^{*}+\frac{R_{g} T_{3}^{*}}{T_{C C}}\left(\dot{m}_{2}+\dot{m}_{\text {fuel }}-\dot{m}_{3}\right)}{}=
\end{gathered}
$$

After involving some simplification, Eq. (9) takes the form: In Eq. (10) $\dot{m}_{2}$ is the air mass flow rate at the compressor discharge, $\dot{m}_{\text {fuel }}$ is the fuel mass flow rate and $\dot{m}_{3}$ is the gas mass flow rate into the turbine inlet.

The change in turbine inlet stagnation temperature $T_{3}{ }^{*}$ is depending on the energy balance of the combustion chamber: enthalpies of incoming and discharging flows as well as the heat supplied by the combustion process. Here $c_{v}$ is the specific heat of the gas at constant volume, $i_{2}{ }^{*}$ and $i_{3}{ }^{*}$ are the stagnation enthalpies at the compressor discharge and turbine inlet, $H_{a}$ stands for the calorific value of the fuel, while $\eta_{C}$ is the efficiency of the combustion process.

$$
\begin{gathered}
\dot{T}_{3}^{*}=\frac{1}{c_{v} m_{C C}}\left[\left(i_{2}^{*} \dot{m}_{2}+H_{a} \eta_{C} \dot{m}_{\text {fuel }}-i_{3}^{*} \dot{m}_{3}\right)-\right. \\
\left.-c_{v} T_{3}^{*}\left(\dot{m}_{2}+\dot{m}_{\text {fuel }}-\dot{m}_{3}\right)\right]
\end{gathered}
$$

In the exhaust nozzle inlet the total pressure $p_{6}{ }^{*}$ and temperature $T_{6}^{*}$ development is similar, but the possibility of fuel injection for thrust augmentation (afterburning) is omitted in the present investigation as none of the turbojets involved contain such equipment yet.

$$
\begin{gathered}
\dot{p}_{6}^{*}=\frac{p_{6}^{*}}{T_{6}^{*}} \dot{T}_{6}^{*}+\frac{R_{g} T_{6}^{*}}{V_{N}}\left(\dot{m}_{6}-\dot{m}_{8}\right) \\
\dot{T}_{6}^{*}=\frac{1}{c_{v} m_{N}}\left[\left(i_{6}^{*} \dot{m}_{6}-i_{8}^{*} \dot{m}_{8}\right)-c_{v} T_{6}^{*}\left(\dot{m}_{6}-\dot{m}_{8}\right)\right]
\end{gathered}
$$

In Eq. (12) and (13) $V_{N}$ and $m_{N}$ are the volume and mass contained in the interstage area between turbine and exhaust nozzle; $i_{6}{ }^{*}$ and $i_{8}{ }^{*}, \dot{m}_{6}$ and $\dot{m}_{8}$ are the stagnation enthalpies and mass flow rates at the nozzle inlet and outlet, respectively.

\subsection{Evaluation of members of governing equations}

In every main governing equation we must specify the dependency on the members of state vector, which is important later when the partial differentials are computed for the linearization.

In Eq. (8) the turbine power $P_{T}$ and compressor power $P_{C}$ can be expressed as a function of mass flow rate, inlet temperature to the given device, pressure ratio and efficiency of that unit, as shown in Eq. (14). 


$$
\begin{aligned}
& P_{T}=\dot{m}_{3} c_{p g} T_{3}^{*}\left[1-\left(\frac{p_{6}^{*}}{\sigma_{D} p_{3}^{*}}\right)^{\frac{\kappa_{g}-1}{\kappa_{g}}}\right] \eta_{T} \\
& P_{C}=\frac{\dot{m}_{2} c_{p a} T_{1}^{*}}{(1-\delta) \eta_{C}}\left[\left(\frac{p_{3}^{*}}{\sigma_{C C} p_{1}^{*}}\right)^{\frac{\kappa_{a}-1}{\kappa_{a}}}-1\right]
\end{aligned}
$$

In Eq. (14) $c_{p g}$ and $c_{p a}$ refer to the gas and air isobaric specific heat, $\kappa_{g}$ and $\kappa_{a}$ stand for the adiabatic exponents of gas and air, $\sigma_{C C}$ and $\sigma_{D}$ are the pressure recovery factors of combustion chamber and diffuser between turbine and exhaust nozzle, $p_{1}{ }^{*}$ and $T_{1}^{*}$ are the compressor inlet stagnation pressure and temperatures. The compressor and turbine efficiencies are marked with $\eta_{C}$ and $\eta_{T}$, respectively.

Each air and gas mass flow rate can be expressed as gas dynamic function dimensionless mass flow $q(\lambda)$ in the following form:

$$
\dot{m}=\frac{p^{*} A \beta q(\lambda)}{\sqrt{T^{*}}}
$$

Area $A$ and gas constant $\beta$ can be referred as constant values, except for the $A_{8}$ outlet are in $\dot{m}_{8}$ mass flow rate of exhaust nozzle. That means each mass flow rate can be expressed as function of total pressure and temperature and dimensionless mass flow rate. It can be shown that the $q(\lambda)$ itself is a function of the given unit's pressure ratio and corrected rotor speed, which can be split into inlet and outlet pressure, inlet temperature, and rotor speed, according to Elkhateeb, Badr and Abouelsoud (2014):

$$
\begin{aligned}
& q\left(\lambda_{1}\right)=f\left(n_{\text {corr }}, \pi_{C}^{*}\right) ; \quad n_{\text {corr }}=\frac{n}{\sqrt{T_{1}^{*}}} ; \\
& \pi_{C}^{*}=\frac{p_{2}^{*}}{p_{1}^{*}}=\frac{p_{3}^{*}}{\sigma_{C C} p_{1}^{*}} ; \quad q\left(\lambda_{1}\right)=f\left(n, p_{3}^{*}, p_{1}^{*}, T_{1}^{*}\right)
\end{aligned}
$$

In Eq. (16) $n_{\text {corr }}$ is the corrected speed of the rotor defined as the ratio of physical rotor speed and square root of compressor inlet temperature, $\pi_{c}^{*}$ represent the total pressure ratio of the compressor. Compressor discharge pressure $p_{2}{ }^{*}$ can be expressed as the combustor pressure $p_{3}{ }^{*}$ divided by the pressure recovery factor $\sigma_{C C}$.

$$
\begin{aligned}
& q\left(\lambda_{3}\right)=f\left(\lambda_{u}, \pi_{T}^{*}\right) ; \quad \pi_{T}^{*}=\frac{p_{3}^{*}}{p_{4}^{*}}=\frac{p_{3}^{*} \sigma_{D}}{p_{6}^{*}} \\
& \lambda_{u}=\frac{D \pi n}{\sqrt{\frac{2 \kappa_{g}}{\kappa_{g}+1} R_{g} T_{3}^{*}}}=f\left(n, T_{3}^{*}\right) \\
& q\left(\lambda_{3}\right)=f\left(n, p_{3}^{*}, p_{6}^{*}, T_{3}^{*}\right)
\end{aligned}
$$

In Eq. (17), $\pi_{T}^{*}$ is the turbine total pressure ratio, $\sigma_{D}$ is the total pressure recovery factor of the diffuser between turbine and exhaust, $\lambda_{u}$ is the dimensionless circumferential velocity, similar to the corrected speed at the compressor. It is the ratio of tangential speed $u$ and the critical speed $c_{\text {crit }}$, yielding a function of rotor speed $n$ and turbine inlet total temperature $T_{3}{ }^{*}$. The turbine discharge pressure $p_{4}{ }^{*}$ in the pressure ratio of the turbine $\pi_{T}^{*}$ is obtained from exhaust nozzle inlet pressure $p_{6}{ }^{*}$ and $\sigma_{D}$ pressure recovery factor.

In Eq. (12) and (13) the exhaust nozzle inlet mass flow can be expressed as sum of the turbine inlet mass flow rate and the amount of cooling air from the turbine, which can be calculated as the percentage of the basic gas flow $\delta_{T C}$.

$$
\begin{aligned}
& \dot{m}_{6}=\dot{m}_{3}\left(1+\delta_{T C}\right)=\frac{\left(1+\delta_{T C}\right) p_{3}^{*} A_{3} \beta_{g} q\left(\lambda_{3}\right)}{\sqrt{T_{3}^{*}}} \\
& q\left(\lambda_{6}\right)=\left(1+\delta_{T C}\right) q\left(\lambda_{3}\right)
\end{aligned}
$$

The dimensionless mass flow rate at the nozzle discharge does not depend on the rotor speed, only pressures and temperatures have an effect.

The pressure recovery factors $\sigma_{C C}$ and $\sigma_{D}$ are changing throughout the whole operating range of the gas turbine, but for the linear model, in a close vicinity of a selected operational point, they can be handled as constants in the present article.

The compressor efficiency $\eta_{C}$ is significantly changing in a narrow neighborhood of a given operational point; it must be expressed as the function of corrected rotor speed and either pressure ratio or dimensionless mass flow rate. As the TKT-1 and iSTC-21v engines include a centrifugal compressor, which pressure ratio does not change significantly at a given corrected speed, but the dimensionless mass flow rate range is significant, in contrast to axial compressors, here we decided to use a function of corrected speed and dimensionless mass flow rate.

$$
\eta_{C}=f\left(n_{\text {corr }}, q\left(\lambda_{1}\right)\right)=f\left(n, p_{3}^{*}, p_{1}^{*}, T_{1}^{*}\right)
$$

The turbine efficiency is changing very slowly in a wide range of turbine pressure ratio, i.e. it can be considered as constant in a narrow environment of the selected operational point.

\subsection{Approximation of state variable dependencies}

For the linear representation of the system, one must obtain such correlations, which describe the dependencies of given parameters (e.g. compressor efficiency) on the members of the state vector. In our investigation we use bilinear approximation, as it has been shown in Ailer, Sánta, Szederkényi and Hangos (2001) that they result in sufficient accuracy while they provide simplicity against higher order approximations.

First let us consider the dimensionless mass flow rate of the compressor. Its description in the original variables $n_{\text {corr }}$ and $\pi_{C}$ as well as the transformed variation can be seen in Eq. (20).

$$
\begin{aligned}
q\left(\lambda_{1}\right) & =a_{1} n_{\text {corr }} \pi_{C}+a_{2} n_{\text {corr }}+a_{3} \pi_{C}+a_{4} \\
& =\frac{a_{1} n}{\sqrt{T_{1}^{*}}} \frac{p_{3}^{*}}{\sigma_{C C} p_{1}^{*}}+\frac{a_{2} n}{\sqrt{T_{1}^{*}}}+\frac{a_{3} p_{3}^{*}}{\sigma_{C C} p_{1}^{*}}+a_{4}
\end{aligned}
$$


The efficiency of the compressor is the function of corrected speed and dimensionless mass flow rate presented in Eq. (21).

$$
\begin{aligned}
\eta_{C}= & b_{1} n_{\text {corr }} q\left(\lambda_{1}\right)+b_{2} q\left(\lambda_{1}\right)+b_{3} n_{\text {corr }}+b_{4} \\
= & \frac{b_{1} n}{\sqrt{T_{1}^{*}}}\left(\frac{a_{1} n}{\sqrt{T_{1}^{*}}} \frac{p_{3}^{*}}{\sigma_{C C} p_{1}^{*}}+\frac{a_{2} n}{\sqrt{T_{1}^{*}}}+\frac{a_{3} p_{3}^{*}}{\sigma_{C C} p_{1}^{*}}+a_{4}\right) \\
& +b_{2}\left(\frac{a_{1} n}{\sqrt{T_{1}^{*}}} \frac{p_{3}^{*}}{\sigma_{C C} p_{1}^{*}}+\frac{a_{2} n}{\sqrt{T_{1}^{*}}}+\frac{a_{3} p_{3}^{*}}{\sigma_{C C} p_{1}^{*}}+a_{4}\right) \\
& +b_{3} \frac{n}{\sqrt{T_{1}^{*}}}+b_{4}
\end{aligned}
$$

From the turbine static characteristics, only the dimensionless mass flow rate $q\left(\lambda_{3}\right)$ is interesting, as the efficiency $\eta_{T}$ exhibits only minimal change over a wide range of pressure ratio. For this expression, first we must collect the turbine related constants from Eq. (17) as follows:

$$
\frac{D \pi}{\sqrt{\frac{2 \kappa_{g}}{\kappa_{g}+1} R_{g}}}=K_{T} \rightarrow \lambda_{u}=\frac{K_{T} n}{\sqrt{T_{3}^{*}}}
$$

With this simplification, we can write the bilinear form of (17) as follows:

$$
\begin{aligned}
q\left(\lambda_{3}\right) & =c_{1} \lambda_{u} \pi_{T}+c_{2} \lambda_{u}+c_{3} \pi_{T}+c_{4} \\
& =\frac{c_{1} K_{T} n}{\sqrt{T_{3}^{*}}} \frac{\sigma_{D} p_{3}^{*}}{p_{6}^{*}}+\frac{c_{2} K_{T} n}{\sqrt{T_{3}^{*}}}+\frac{c_{3} \sigma_{D} p_{3}^{*}}{p_{6}^{*}}+a_{4}
\end{aligned}
$$

\section{Development of the linearized mathematical model}

\subsection{Partial derivatives of state variables}

One must collect 25 partial derivatives to build matrix A and ten derivatives for matrix $\mathbf{B}$, as shown in Eq, (24), where the indices $i, j$ and $k$ have the ranges of [1..5], [1..5] and [1..2], respectively.

$$
\begin{aligned}
& \mathbf{A}=\left[\frac{\partial f_{i}}{\partial x_{j}}\right] \\
& \mathbf{B}=\left[\frac{\partial f_{i}}{\partial u_{k}}\right]
\end{aligned}
$$

\subsubsection{Partial derivatives of the rotor speed}

In this section we summarize the partial derivatives of rotor speed by state and control variables.

The dynamic Eq. (8) contains rotor speed in its nominator, and rotor speed can be found in the turbine and compressor powers $P_{T}$ and $P_{C}$, as the dimensionless mass flow rates $q\left(\lambda_{3}\right)$ and $q\left(\lambda_{1}\right)$ and compressor efficiency depend on rotor speed $\mathrm{n}$. In Eq. (25), all other state variables than $n$ and input variables are considered as constant.

$$
\begin{aligned}
d \dot{n} & =\frac{\partial \dot{n}}{\partial n} d n+\frac{\partial \dot{n}}{\partial P_{T}} \frac{\partial P_{T}}{\partial q\left(\lambda_{3}\right)} \frac{\partial q\left(\lambda_{3}\right)}{\partial n} d n \\
& +\frac{\partial \dot{n}}{\partial P_{C}} \frac{\partial P_{C}}{\partial q\left(\lambda_{1}\right)} \frac{\partial q\left(\lambda_{1}\right)}{\partial n} d n+\frac{\partial \dot{n}}{\partial P_{C}} \frac{\partial P_{C}}{\partial \eta_{C}} \frac{\partial \eta_{C}}{\partial n} d n
\end{aligned}
$$

The first term is obtained by simple derivation of Eq. (8) by rotor speed $n$ yielding Eq. (26):

$$
\frac{\partial \dot{n}}{\partial n}=-\frac{P_{T} \eta_{m}-P_{C}}{\Theta(\pi / 30)^{2} n^{2}}=-\frac{\dot{n}}{n}
$$

The second and third terms are similar in buildup, but it is important that the $P_{C}$ compressor power has a negative sign.

$$
\begin{aligned}
& \frac{\partial \dot{n}}{\partial P_{T}} \frac{\partial P_{T}}{\partial q\left(\lambda_{3}\right)} \frac{\partial q\left(\lambda_{3}\right)}{\partial n}=\frac{P_{T} \eta_{m}}{n \Theta(\pi / 30)^{2} q\left(\lambda_{3}\right)} \frac{K_{T} C_{T}^{n}}{\sqrt{T_{3}^{*}}} \\
& \frac{\partial \dot{n}}{\partial P_{C}} \frac{\partial P_{C}}{\partial q\left(\lambda_{1}\right)} \frac{\partial q\left(\lambda_{1}\right)}{\partial n}=-\frac{P_{C}}{n \Theta(\pi / 30)^{2} q\left(\lambda_{1}\right)} \frac{C_{C}^{n}}{\sqrt{T_{1}^{*}}}
\end{aligned}
$$

In Eq. (27) the $C_{C}{ }^{n}$ and $C_{T}{ }^{n}$ constants are the following:

$$
C_{T}^{n}=\frac{c_{1} \sigma_{D} p_{3}^{*}}{p_{6}^{*}}+c_{2} ; \quad C_{C}^{n}=\left(\frac{a_{1} p_{3}^{*}}{\sigma_{C C} p_{1}^{*}}+a_{2}\right)
$$

The compressor efficiency has such an influence on the rotor speed derivative:

$$
\begin{aligned}
& \frac{\partial \dot{n}}{\partial P_{C}} \frac{\partial P_{C}}{\partial \eta_{C}} \frac{\partial \eta_{C}}{\partial n}=\frac{P_{C}}{n \Theta(\pi / 30)^{2} \eta_{C}}\left[\frac{2 b_{1} n}{T_{1}^{*}} C_{C}^{n}+\right. \\
& \left.+\frac{p_{3}^{*}\left(b_{1} a_{3}+b_{3} a_{1}\right)}{\sigma_{C C} p_{1}^{*} \sqrt{T_{1}^{*}}}+\frac{\left(b_{1} a_{4}+b_{2}+b_{3} a_{2}\right)}{\sqrt{T_{1}^{*}}}\right]
\end{aligned}
$$

The rotor speed has also a dependency on turbine inlet pressure $p_{3}{ }^{*}$, as it is contained in both turbine and compressor power. Holding all other values as constant, the differential change in rotor speed caused by $p_{3}{ }^{*}$ is as follows:

$$
\begin{aligned}
d \dot{n}= & \frac{\partial \dot{n}}{\partial P_{T}} \frac{\partial P_{T}}{\partial \dot{m}_{3}} \frac{\partial \dot{m}_{3}}{\partial p_{3}^{*}} d p_{3}^{*}+\frac{\partial \dot{n}}{\partial P_{T}} \frac{\partial P_{T}}{\partial q\left(\lambda_{3}\right)} \frac{\partial q\left(\lambda_{3}\right)}{\partial p_{3}^{*}} d p_{3}^{*}+\frac{\partial P_{T}}{\partial p_{3}^{*}} d p_{3}^{*} \\
& +\frac{\partial \dot{n}}{\partial P_{C}} \frac{\partial P_{C}}{\partial q\left(\lambda_{1}\right)} \frac{\partial q\left(\lambda_{1}\right)}{\partial p_{3}^{*}} d p_{3}^{*}+\frac{\partial \dot{n}}{\partial P_{C}} \frac{\partial P_{C}}{\partial p_{3}^{*}} d p_{3}^{*}+\frac{\partial \dot{n}}{\partial P_{C}} \frac{\partial P_{C}}{\partial \eta_{C}} \frac{\partial \eta_{C}}{\partial p_{3}^{*}} d p_{3}^{*}
\end{aligned}
$$

Those members of Eq. (30), which have not been detailed before, are the following, including new definitions for constants, which will be used later in this article:

$$
\begin{aligned}
& \frac{\partial \dot{m}_{3}}{\partial p_{3}^{*}}=\frac{\dot{m}_{3}}{p_{3}^{*}} ; \quad \frac{\partial q\left(\lambda_{3}\right)}{\partial p_{3}^{*}}=\frac{\sigma_{D}}{p_{6}^{*}}\left(\frac{c_{1} K_{T} n}{\sqrt{T_{3}^{*}}}+c_{3}\right)=\frac{\sigma_{D}}{p_{6}^{*}} C_{T}^{p_{3}^{*}} \\
& \frac{\partial q\left(\lambda_{1}\right)}{\partial p_{3}^{*}}=\frac{1}{\sigma_{C C} p_{1}^{*}}\left(\frac{a_{1} n}{\sqrt{T_{1}^{*}}}+a_{3}\right)=\frac{C_{C}^{p_{3}^{*}}}{\sigma_{C C} p_{1}^{*}}
\end{aligned}
$$




$$
\begin{aligned}
& \frac{\partial P_{T}}{\partial p_{3}^{*}}=\frac{\dot{m}_{3} c_{p g} T_{3}^{*} \eta_{T}}{p_{3}^{*}} \frac{\kappa_{g}-1}{\kappa_{g}}\left(\frac{p_{6}^{*}}{\sigma_{D} p_{3}^{*}}\right)^{\frac{\kappa_{g}-1}{\kappa_{g}}} \\
& \frac{\partial P_{C}}{\partial p_{3}^{*}}=\frac{\dot{m}_{2} c_{p a} T_{1}^{*}\left(\kappa_{a}-1\right)}{(1-\delta) \eta_{C} \kappa_{a} p_{3}^{*}}\left(\frac{p_{3}^{*}}{\sigma_{C C} p_{1}^{*}}\right)^{\frac{\kappa_{a}-1}{\kappa_{a}}} \\
& \frac{\partial \eta_{C}}{\partial p_{3}^{*}}=\frac{\left[\frac{n}{\sqrt{T_{1}^{*}}}\left(b_{1} a_{1} \frac{n}{\sqrt{T_{1}^{*}}}+b_{1} a_{3}+b_{3} a_{1}\right)+b_{3} a_{3}\right]}{\sigma_{C C} p_{1}^{*}}=\frac{C_{\eta_{C}}^{p^{*}}}{\sigma_{C C} p_{1}^{*}}
\end{aligned}
$$

Equation (8) also contains members depending on the $T_{3}{ }^{*}$ turbine inlet total temperature. These are collected in Eq. (33), maintaining all variables other than $T_{3}^{*}$ at constant values.

$$
\begin{aligned}
& d \dot{n}=\frac{\partial \dot{n}}{\partial P_{T}} \frac{\partial P_{T}}{\partial T_{3}^{*}} d T_{3}^{*}+\frac{\partial \dot{n}}{\partial P_{T}} \frac{\partial P_{T}}{\partial \dot{m}_{3}} \frac{\partial \dot{m}_{3}}{\partial T_{3}^{*}} d T_{3}^{*}+ \\
& +\frac{\partial \dot{n}}{\partial P_{T}} \frac{\partial P_{T}}{\partial q\left(\lambda_{3}\right)} \frac{\partial q\left(\lambda_{3}\right)}{\partial T_{3}^{*}} d T_{3}^{*}
\end{aligned}
$$

The various partial derivatives appearing in Eq. (33) can be evaluated in Eq. (34).

$$
\frac{\partial \dot{m}_{3}}{\partial T_{3}^{*}}=-\frac{\dot{m}_{3}}{2 T_{3}^{*}} ; \quad \frac{\partial P_{T}}{\partial T_{3}^{*}}=\frac{P_{T}}{T_{3}^{*}} ; \quad \frac{\partial q\left(\lambda_{3}\right)}{\partial T_{3}^{*}}=-\frac{K_{T} n}{2 T_{3}^{*} \sqrt{T_{3}^{*}}} C_{T}^{n}
$$

The rotor speed - due to the turbine power - also depends on the turbine discharge pressure $p_{4}{ }^{*}$, which can be expressed as the ratio of $p_{6}{ }^{*}$ exhaust nozzle inlet pressure and $\sigma_{D}$ pressure recovery factor, thus the dependency on the next state variable can be defined as found in Eq. (35).

$$
d \dot{n}=\frac{\partial \dot{n}}{\partial P_{T}} \frac{\partial P_{T}}{\partial q\left(\lambda_{3}\right)} \frac{\partial q\left(\lambda_{3}\right)}{\partial p_{6}^{*}} d p_{6}^{*}+\frac{\partial P_{T}}{\partial p_{6}^{*}} d p_{6}^{*}
$$

The previous partial derivatives are calculated as follows:

$$
\begin{aligned}
& \frac{\partial q\left(\lambda_{3}\right)}{\partial p_{6}^{*}}=-\frac{c_{1} K_{T} n \sigma_{D} p_{3}^{*}}{\sqrt{T_{3}^{*}} p_{6}^{* 2}}-\frac{c_{3} \sigma_{D} p_{3}^{*}}{p_{6}^{* 2}}=-\frac{\sigma_{D} p_{3}^{*}}{p_{6}^{* 2}} C_{T}^{p_{3}^{*}} \\
& \frac{\partial P_{T}}{\partial p_{6}^{*}}=-\dot{m}_{3} c_{p g} T_{3}^{*} \eta_{T} \frac{\kappa_{g}-1}{\kappa_{g}} \frac{1}{\pi_{T}^{*} \frac{\kappa_{g}-1}{\kappa_{g}}} \frac{1}{p_{6}^{*}}
\end{aligned}
$$

The rotor speed does not contain any direct dependency on the exhaust nozzle inlet total temperature, mass flow rate of the fuel and exhaust nozzle outlet area, so the last derivative of matrix $\mathbf{A}$ and the first row of $\mathbf{B}$ is zero:

$$
\frac{\partial \dot{n}}{\partial T_{6}^{*}}=0 ; \quad \frac{\partial \dot{n}}{\partial \dot{m}_{\text {fuel }}}=0 ; \quad \frac{\partial \dot{n}}{\partial A_{8}}=0
$$

\subsubsection{Partial derivatives of turbine inlet total pressure}

One must split the mass flow rates of Eq. (10) into gas dynamic expressions in order to gain the partial derivatives on the variables mentioned in the previous section.

First we consider the derivative by rotor speed, which has dependencies in the compressor and turbine mass flow rates:

$$
\frac{\partial \dot{p}_{3}^{*}}{\partial n}=\frac{R_{g} T_{3}^{*}}{V_{C C}}\left[\frac{\dot{m}_{2}}{q\left(\lambda_{1}\right)} \frac{C_{C}^{n}}{\sqrt{T_{1}^{*}}}-\frac{\dot{m}_{3}}{q\left(\lambda_{3}\right)} \frac{K_{T}}{\sqrt{T_{3}^{*}}} C_{T}^{n}\right]
$$

The derivative by $p_{3}{ }^{*}$ itself will contain parts from the first member of Eq. (10), and the mass flow rates of compressor and turbine, as detailed in the previous section.

$$
\frac{\partial \dot{p}_{3}^{*}}{\partial p_{3}^{*}}=\frac{\dot{T}_{3}^{*}}{T_{3}^{*}}+\frac{R_{g} T_{3}^{*}}{V_{C C}}\left\{\frac{\dot{m}_{2}}{q\left(\lambda_{1}\right)} \frac{C_{C}^{p_{3}^{*}}}{\sigma_{C C} p_{1}^{*}}-\left[\frac{\dot{m}_{3}}{p_{3}^{*}}+\frac{\dot{m}_{3}}{q\left(\lambda_{3}\right)} \frac{\sigma_{D}}{p_{6}^{*}} C_{T}^{p_{3}^{*}}\right]\right\}
$$

The derivative by $T_{3}^{*}$ contains the member obtained from the first part of the original expression and the second member is split into two parts according to the law of the derivative of a product.

$$
\begin{aligned}
\frac{\partial \dot{p}_{3}^{*}}{\partial T_{3}^{*}}= & -\frac{p_{3}^{*}}{T_{3}^{* 2}} \dot{T}_{3}^{*}+\frac{R_{g}}{V_{C C}}\left(\dot{m}_{2}+\dot{m}_{\text {fuel }}-\dot{m}_{3}\right) \\
& -\frac{R_{g} T_{3}^{*}}{V_{C C}}\left[-\frac{\dot{m}_{3}}{2 T_{3}^{*}}-\frac{\dot{m}_{3} K_{T} n}{2 q\left(\lambda_{3}\right) T_{3}^{*} \sqrt{T_{3}^{*}}} C_{T}^{n}\right]
\end{aligned}
$$

The next step is to evaluate the derivative by the exhaust nozzle inlet pressure $p_{6}{ }^{*}$, which is found in the dimensionless mass flow rate of the turbine.

$$
\frac{\partial \dot{p}_{3}^{*}}{\partial p_{6}^{*}}=\frac{R_{g} T_{3}^{*}}{V_{C C}}\left[\frac{\dot{m}_{3}}{q\left(\lambda_{3}\right)} \frac{\sigma_{D} p_{3}^{*}}{p_{6}^{* 2}} C_{T}^{p_{3}^{*}}\right]
$$

Equation (10) does not contain neither exhaust nozzle inlet total temperature $T_{6}{ }^{*}$ nor exhaust nozzle outlet area $A_{8}$, so the last member of the second row in $\mathbf{A}$ and $\mathbf{B}$ matrices are equal to zero:

$$
\frac{\partial \dot{p}_{3}^{*}}{\partial T_{6}^{*}}=0 ; \quad \frac{\partial \dot{p}_{3}^{*}}{\partial A_{8}}=0
$$

The fuel mass flow rate is included in Eq. (10) so the turbine inlet total pressure $p_{3}{ }^{*}$ is influenced by this input parameter.

$$
\frac{\partial \dot{p}_{3}^{*}}{\partial \dot{m}_{f u e l}}=\frac{R_{g} T_{3}^{*}}{V_{C C}}
$$

\subsubsection{Partial derivatives of turbine inlet total temperature}

The derivative of total temperature is possibly the most complicated among the dynamic equations of the turbojet. It contains many different mass flow rates as well as temperatures, like $T_{2}^{*}$ compressor discharge temperature, which itself must be expressed as the function of compressor pressure ratio and efficiency, thus involving many approximated components. As in the previous sections, first we investigate the dependency on rotor speed while maintaining all other factors at constant levels.

$$
\begin{aligned}
d \dot{T}_{3}^{*} & =\frac{\partial \dot{T}_{3}^{*}}{\partial q\left(\lambda_{1}\right)} \frac{\partial q\left(\lambda_{1}\right)}{\partial n} d n+\frac{\partial \dot{T}_{3}^{*}}{\partial T_{2}^{*}} \frac{\partial T_{2}^{*}}{\partial \eta_{C}} \frac{\partial \eta_{C}}{\partial n} d n \\
& +\frac{\partial \dot{T}_{3}^{*}}{\partial q\left(\lambda_{3}\right)} \frac{\partial q\left(\lambda_{3}\right)}{\partial n} d n
\end{aligned}
$$


The members of Eq. (44) can be described as follows:

$$
\begin{aligned}
& \frac{\partial \dot{T}_{3}^{*}}{\partial q\left(\lambda_{1}\right)} \frac{\partial q\left(\lambda_{1}\right)}{\partial n}=\frac{\dot{m}_{2}\left(c_{p a} T_{2}^{*}-c_{v} T_{3}^{*}\right)}{m_{C C} c_{v} q\left(\lambda_{1}\right) \sqrt{T_{1}^{*}}} C_{C}^{n} \\
& \frac{\partial \dot{T}_{3}^{*}}{\partial T_{2}^{*}} \frac{\partial T_{2}^{*}}{\partial \eta_{C}} \frac{\partial \eta_{C}}{\partial n}=-\frac{T_{2}^{*}}{\eta_{C}} \frac{\dot{m}_{2} c_{p a}}{m_{C C} c_{v}}\left[\frac{2 b_{1} n}{T_{1}^{*}} C_{C}^{n}+\right. \\
& \left.+\frac{p_{3}^{*}}{\sigma_{C C} p_{1}^{*} \sqrt{T_{1}^{*}}}\left(b_{1} a_{3}+b_{3} a_{1}\right)+\frac{1}{\sqrt{T_{1}^{*}}}\left(b_{1} a_{4}+b_{2}+b_{3} a_{2}\right)\right] \\
& \frac{\partial \dot{T}_{3}^{*}}{\partial q\left(\lambda_{3}\right)} \frac{\partial q\left(\lambda_{3}\right)}{\partial n}=\frac{\dot{m}_{3}}{q\left(\lambda_{3}\right)} \frac{\left(c_{v}-c_{p g}\right) \sqrt{T_{3}^{*}}}{m_{C C} c_{v}} K_{T} C_{T}^{n}
\end{aligned}
$$

The derivative by $p_{3}{ }^{*}$ has the following formula if all other variables are held constant:

$$
\begin{aligned}
\frac{\partial \dot{T}_{3}^{*}}{\partial p_{3}^{*}} & =\frac{\partial \dot{T}_{3}^{*}}{\partial m_{C C}} \frac{\partial m_{C C}}{\partial p_{3}^{*}}+\frac{\partial \dot{T}_{3}^{*}}{\partial q\left(\lambda_{1}\right)} \frac{\partial q\left(\lambda_{1}\right)}{\partial p_{3}^{*}} \\
& +\frac{\partial \dot{T}_{3}^{*}}{\partial T_{2}^{*}}\left(\frac{\partial T_{2}^{*}}{\partial p_{3}^{*}}+\frac{\partial T_{2}^{*}}{\partial \eta_{C}} \frac{\partial \eta_{C}}{\partial p_{3}^{*}}\right)+\frac{\partial \dot{T}_{3}^{*}}{\partial \dot{m}_{3}}\left(\frac{\partial \dot{m}_{3}}{\partial p_{3}^{*}}+\frac{\partial \dot{m}_{3}}{\partial q\left(\lambda_{3}\right)} \frac{\partial q\left(\lambda_{3}\right)}{\partial p_{3}^{*}}\right)
\end{aligned}
$$

These partial derivatives take the following correlations:

$\frac{\partial \dot{T}_{3}^{*}}{\partial m_{C C}} \frac{\partial m_{C C}}{\partial p_{3}^{*}}=-\frac{\dot{T}_{3}^{*} m_{C C}}{m_{C C}{ }^{2} c_{v} p_{3}^{*}} ; \frac{\partial T_{2}^{*}}{\partial \eta_{C}}=-T_{1}^{*}\left[\frac{\left(p_{3}^{*} /\left(\sigma_{C C} p_{1}^{*}\right)\right)^{\frac{\kappa_{a}-1}{\kappa_{a}}}-1}{\eta_{C}^{2}}\right]$

$\frac{\partial \dot{T}_{3}^{*}}{\partial T_{2}^{*}}=\frac{\dot{m}_{2} c_{p a}}{m_{C C} c_{v}} ; \quad \frac{\partial T_{2}^{*}}{\partial p_{3}^{*}}=\frac{T_{1}^{*}}{\eta_{C}} \frac{\kappa_{a}-1}{\kappa_{a}}\left(\frac{p_{3}^{*}}{\sigma_{C C} p_{1}^{*}}\right)^{\frac{\kappa_{a}-1}{\kappa_{a}}} \frac{1}{p_{3}^{*}}$

$\frac{\partial \eta_{C}}{\partial p_{3}^{*}}=\frac{C_{\eta_{C}}^{p_{3}^{*}}}{\sigma_{C C} p_{1}^{*}} ; \quad \frac{\partial \dot{T}_{3}^{*}}{\partial q\left(\lambda_{1}\right)} \frac{\partial q\left(\lambda_{1}\right)}{\partial p_{3}^{*}}=\frac{\dot{m}_{2}\left(c_{p a} T_{2}^{*}-c_{v} T_{3}^{*}\right)}{m_{C C} c_{v} q\left(\lambda_{1}\right) \sigma_{C C} p_{1}^{*}} C_{C}^{p_{3}^{*}}$

$\frac{\partial \dot{T}_{3}^{*}}{\partial \dot{m}_{3}}=\frac{\left(c_{v}-c_{p g}\right) T_{3}^{*}}{m_{C C} c_{v}}\left(\frac{\dot{m}_{3}}{p_{3}^{*}}+\frac{\dot{m}_{3}}{q\left(\lambda_{3}\right)} \frac{\sigma_{D}}{p_{6}^{*}} C_{T}^{p_{3}^{*}}\right)$

There is a strong dependency on the turbine inlet temperature itself, which can be found in the $m_{C C}$ mass in the combustion chamber due to the gas law, in the denominator of the first member of Eq. (11), and in the mass flow rate of the turbine in the gas dynamic expression and in $q\left(\lambda_{3}\right)$.

$$
\frac{\partial \dot{T}_{3}^{*}}{\partial T_{3}^{*}}=\frac{\partial \dot{T}_{3}^{*}}{\partial m_{C C}} \frac{\partial m_{C C}}{\partial T_{3}^{*}}+\frac{\partial \dot{T}_{3}^{*}}{\partial T_{3}^{*}}+\frac{\partial \dot{T}_{3}^{*}}{\partial \dot{m}_{3}}\left(\frac{\partial \dot{m}_{3}}{\partial T_{3}^{*}}+\frac{\partial \dot{m}_{3}}{\partial q\left(\lambda_{3}\right)} \frac{\partial q\left(\lambda_{3}\right)}{\partial T_{3}^{*}}\right)
$$

Those partial differentials, which have appeared in Eq. (48) first, can be expressed as found in (49). As the $m_{C C}$ mass in the combustion chamber is in the denominator of (11) but the gas law expressed for mass contains temperature again in the nominator, the first term's dual negative signs will eliminate each other.

$$
\begin{aligned}
& \frac{\partial \dot{T}_{3}^{*}}{\partial m_{C C}} \frac{\partial m_{C C}}{\partial T_{3}^{*}}=\frac{\dot{T}_{3}^{*}}{m_{C C}{ }^{2} c_{v}} \frac{m_{C C}}{T_{3}^{*}} ; \quad \frac{\partial \dot{T}_{3}^{*}}{\partial \dot{m}_{3}}=\frac{\left(c_{v}-c_{p g}\right) T_{3}^{*}}{m_{C C} c_{v}} \\
& \frac{\partial \dot{m}_{3}}{\partial T_{3}^{*}}=-\frac{\dot{m}_{3}}{2 T_{3}^{*} \sqrt{T_{3}^{*}}} ; \quad \frac{\partial \dot{m}_{3}}{\partial q\left(\lambda_{3}\right)}=\frac{\dot{m}_{3}}{q\left(\lambda_{3}\right)} ; \quad \frac{\partial q\left(\lambda_{3}\right)}{\partial T_{3}^{*}}=-\frac{K_{T} n C_{T}^{n}}{2 T_{3}^{*} \sqrt{T_{3}^{*}}} \\
& \frac{\partial \dot{T}_{3}^{*}}{\partial T_{3}^{*}}=-\frac{c_{p g} \dot{m}_{3}+c_{v}\left(\dot{m}_{2}+\dot{m}_{f u e l}-\dot{m}_{3}\right)}{m_{C C} c_{v}}
\end{aligned}
$$

Equation (11) contains the $p_{6}{ }^{*}$ exhaust nozzle inlet pressure only in the $q\left(\lambda_{3}\right)$ dimensionless mass flow rate of gas. Therefore the applicable partial derivative is as shown in Eq. (50).

$$
\frac{\partial \dot{T}_{3}^{*}}{\partial p_{6}^{*}}=-\frac{\dot{m}_{3}}{q\left(\lambda_{3}\right)} \frac{\left(c_{v}-c_{p g}\right) T_{3}^{*}}{m_{C C} c_{v}} \frac{\sigma_{D} p_{3}^{*}}{p_{6}^{* 2}} C_{T}^{p_{3}^{*}}
$$

Neither $T_{6}^{*}$ exhaust nozzle inlet temperature nor $A_{8}$ nozzle exit area are contained within Eq. (12) thus these derivatives are equal to zero.

$$
\frac{\partial \dot{T}_{3}^{*}}{\partial T_{6}^{*}}=0 ; \quad \frac{\partial \dot{T}_{3}^{*}}{\partial A_{8}}=0
$$

The change of fuel mass flow rate has a simple but very important influence on the turbine inlet temperature, what can be evaluated as Eq. (52).

$$
\frac{\partial \dot{T}_{3}^{*}}{\partial \dot{m}_{f u e l}}=\frac{H_{a} \eta_{C}-c_{v} T_{3}^{*}}{m_{C C} \cdot c_{v}}
$$

\subsubsection{Partial derivatives of exhaust nozzle inlet total pressure}

The deduction of the related partial differentials is very similar to those steps shown in Section 3.2.2 for the turbine inlet total pressure, except for that here we do not include the possibility of afterburning (thrust augmentation) i.e. there is no fuel supply and combustion downstream the turbine. This fact will simplify the correlations for both pressure and temperature at the exhaust nozzle.

First we must consider such a form of Eq. (12), which contains the correlation to the main variables. This means not only to change mass flow rates into gas dynamic equivalents, but it is important to express the nozzle inlet mass flow rate as a function of turbine inlet mass flow rate. The difference between these two is the cooling flow that joins through the turbine and participates in the flow at the nozzle. This flow has a relative amount compared to the turbine inlet mass flow as shown in Eq. (18).

Similarly, the nozzle outlet flow can be expressed with the stagnation properties at that station; one must consider a small pressure loss along the nozzle, which can be taken into account as a $\sigma_{N}$ pressure recovery factor of exhaust nozzle; the total temperature does not change as there is no energy change throughout the expansion in the nozzle.

$$
\dot{m}_{8}=\frac{\left(p_{6}^{*} \sigma_{N}\right) \beta_{g} A_{8} q\left(\lambda_{8}\right)}{\sqrt{T_{6}^{*}}}
$$


Thus, the rotor speed can be found in the dimensionless mass flow rate of the turbine; the last exhaust $q\left(\lambda_{8}\right)$ does not include this variable, so the appropriate partial derivative is as displayed in Eq. (54).

$$
\frac{\partial \dot{p}_{6}^{*}}{\partial n}=\frac{\partial \dot{p}_{6}^{*}}{\partial \dot{m}_{6}} \frac{\partial \dot{m}_{6}}{\partial q\left(\lambda_{3}\right)} \frac{\partial q\left(\lambda_{3}\right)}{\partial n}=\frac{R_{g} T_{6}^{*}}{V_{D}} \frac{\dot{m}_{6}}{q\left(\lambda_{3}\right)} \frac{K_{T}}{\sqrt{T_{3}^{*}}} C_{T}^{n}
$$

The turbine inlet total pressure $p_{3}{ }^{*}$ can be found implicitly in the inlet mass flow rate of the exhaust nozzle, so the respective partial differential is shown in Eq. (55).

$$
\begin{aligned}
\frac{\partial \dot{p}_{6}^{*}}{\partial p_{3}^{*}} & =\frac{\partial \dot{p}_{6}^{*}}{\partial \dot{m}_{6}}\left(\frac{\partial \dot{m}_{6}}{\partial p_{3}^{*}}+\frac{\partial \dot{m}_{6}}{\partial q\left(\lambda_{3}\right)} \frac{\partial q\left(\lambda_{3}\right)}{\partial p_{3}^{*}}\right) \\
& =\frac{R_{g} T_{6}^{*}}{V_{D}}\left[\frac{\dot{m}_{6}}{p_{3}^{*}}+\frac{\dot{m}_{6}}{q\left(\lambda_{3}\right)} \frac{\sigma_{D}}{p_{6}^{*}} C_{T}^{p_{3}^{*}}\right]
\end{aligned}
$$

The turbine inlet total temperature works similarly to the previous paragraph so it is implicitly hidden in the inlet mass flow rate of the exhaust nozzle, shown in (56).

$$
\begin{aligned}
\frac{\partial \dot{p}_{6}^{*}}{\partial T_{3}^{*}} & =-\frac{R_{g} T_{6}^{*}}{2 V_{D}}\left[\frac{\partial \dot{m}_{6}}{\partial T_{3}^{*}}+\frac{\partial \dot{m}_{6}}{\partial q\left(\lambda_{3}\right)} \frac{\partial q\left(\lambda_{3}\right)}{\partial T_{3}^{*}}\right] \\
& =-\frac{R_{g} T_{6}^{*}}{2 T_{3}^{*} V_{D}} \cdot\left[\dot{m}_{3}\left(1+\delta_{T C}\right)+\frac{K_{T} n}{\sqrt{T_{3}^{*}}} C_{T}^{n}\right]
\end{aligned}
$$

The investigation must consider the $q\left(\lambda_{8}\right)$ dimensionless mass flow rate as well, as it is an inevitable component of Eq. (12) and (13). For the deduction, we must find the appropriate origin, which can be the reversal of the gas dynamic expression for the mass flow rate.

$$
\begin{aligned}
q\left(\lambda_{8}\right) & =\frac{\dot{m}_{8} \sqrt{T_{8}^{*}}}{p_{8}^{*} A_{8} \beta_{g}}=\frac{\rho_{8}}{\rho_{8}} \frac{\dot{m}_{8} \sqrt{T_{8}^{*}}}{p_{8}^{*} A_{8} \beta_{g}}=\frac{\rho_{8} c_{8} \sqrt{T_{8}^{*}}}{p_{8}^{*} \beta_{g}} \\
& =\frac{\rho_{8} c_{8} \sqrt{T_{8}^{*}}}{p_{8}^{*} \beta_{g}} \frac{\sqrt{T_{8}^{*}}}{\sqrt{T_{8}^{*}}} \frac{\rho_{8}^{*}}{\rho_{8}^{*}}=\frac{\rho_{8} c_{8}}{\rho_{8}^{*} \beta_{g} \sqrt{T_{8}^{*}}}=\left(\frac{p_{8}}{p_{8}^{*}}\right)^{\frac{1}{\kappa_{g}}} \frac{c_{8}}{\beta_{g} R_{g} \sqrt{T_{8}^{*}}}
\end{aligned}
$$

In Eq. (57) one must consider the energy equation to express the velocity $c_{8}$ and due to the lack of energy change $T_{8}{ }^{*}$ will be substituted by $T_{6}{ }^{*}$. For the pressures, supposing real flow conditions, the $p_{8}{ }^{*}$ is not equal to $p_{6}{ }^{*}$ but there is the $\sigma_{N}$ pressure recovery factor between them. Considering moderate nozzle pressure ratios, which are typically around 1.2:1 for both engines under investigation, we can say, they are far below the critical pressure, i.e. both operate with total expansion in their convergent exhaust nozzles. This immediately determines the formula for the velocity. So the final expression for $q\left(\lambda_{8}\right)$ including detailed description of gas constant $\beta_{g}$ can be found in Eq. (58). This expression also introduced some simplifications, which will ease the deduction of the partial derivative as well. Here, $\delta_{N}$ stands for the expansion ratio of the exhaust nozzle (reciprocal of pressure ratio), $\tau_{\text {crit }}$ is the critical temperature ratio and $\psi_{N}$ is a complex expression built from velocity $c_{8}, \beta_{g}$ members and square root of $T_{6}^{*}$ total temperature.

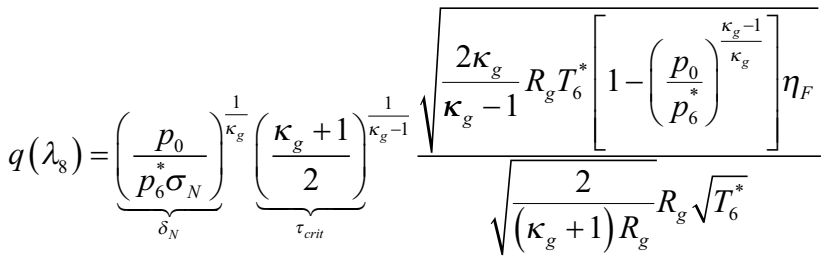

$$
\begin{aligned}
& =\delta_{N}^{\frac{1}{\kappa_{g}}} \tau_{\text {crit }}^{\frac{1}{\kappa_{g}-1}} \underbrace{\sqrt{\frac{\left(\kappa_{g}+1\right) \kappa_{g}}{\kappa_{g}-1}\left[1-\left(\frac{p_{0}}{p_{6}^{*}}\right)^{\frac{\kappa_{g}-1}{\kappa_{g}}}\right]} \eta_{F}}_{\psi_{N}}=\delta_{N}^{\frac{1}{\kappa_{g}}} \tau_{\text {crit }}^{\frac{1}{\kappa_{g}-1}} \psi_{N}
\end{aligned}
$$

The $q\left(\lambda_{8}\right)$ dimensionless mass flow rate is practically depending only on $p_{6}{ }^{*}$ from the state and input variables. All other members of (58) can be considered as constants. Therefore it must be taken into account when elaborating the partial differential for the $p_{6}{ }^{*}$ pressure. The partial derivative is shown in Eq. (59) explaining all members, except for $q\left(\lambda_{8}\right)$, which is considered below due to its higher complexity.

$$
\begin{aligned}
\frac{\partial \dot{p}_{6}^{*}}{\partial p_{6}^{*}} & =\frac{\dot{T}_{6}^{*}}{T_{6}^{*}}-\frac{R_{g} T_{6}^{*}}{V_{D}}\left(\frac{\partial \dot{m}_{8}}{\partial p_{6}^{*}}+\frac{\partial \dot{m}_{6}}{\partial q\left(\lambda_{3}\right)} \frac{\partial q\left(\lambda_{3}\right)}{\partial p_{6}^{*}}+\frac{\partial \dot{m}_{8}}{\partial q\left(\lambda_{8}\right)} \frac{\partial q\left(\lambda_{8}\right)}{\partial p_{6}^{*}}\right) \\
& =\frac{\dot{T}_{6}^{*}}{T_{6}^{*}}-\frac{R_{g} T_{6}^{*}}{V_{D}}\left[\frac{\dot{m}_{8}}{p_{6}^{*}}-\frac{\dot{m}_{6}}{q\left(\lambda_{3}\right)} \frac{\sigma_{D} p_{3}^{*}}{p_{6}^{* 2}} C_{T}^{p_{3}^{*}}-\frac{\dot{m}_{8}}{q\left(\lambda_{8}\right)} \frac{\partial q\left(\lambda_{8}\right)}{\partial p_{6}^{*}}\right]
\end{aligned}
$$

The last partial derivative can be found in Eq. (60), deduced from Eq. (58).

$$
\frac{\partial q\left(\lambda_{8}\right)}{\partial p_{6}^{*}}=-\frac{\delta_{N}{ }^{\frac{1}{\kappa_{g}}} \tau_{c r i t}{ }^{\frac{1}{\kappa_{g}-1}} \psi_{N}}{\kappa_{g} p_{6}^{*}}+\frac{\delta_{N}{ }^{\frac{1}{\kappa_{g}}} \tau_{c r i t}{ }^{\frac{1}{\kappa_{g}-1}}}{2 \kappa_{g} p_{6}^{*} \psi_{N}}\left(\kappa_{g}+1\right) \eta_{N}\left(\frac{p_{0}}{p_{6}^{*}}\right)^{\frac{\kappa_{g}-1}{\kappa_{g}}}
$$

Equation (12) includes explicit and implicit dependency on the exhaust nozzle inlet stagnation temperature $T_{6}{ }^{*}$. The related partial derivative is displayed in Eq. (61).

$$
\frac{\partial \dot{p}_{6}^{*}}{\partial T_{6}^{*}}=-\frac{p_{6}^{*}}{T_{6}^{* 2}} \dot{T}_{6}^{*}+\frac{R_{g}\left(\dot{m}_{6}-\dot{m}_{8}\right)}{V_{D}}+\frac{R_{g} \dot{m}_{8}}{2 V_{D}}
$$

As Eq. (12) does not contain fuel mass flow rate in any form, the corresponding partial derivative is zero. The outlet area $A_{8}$ is a simple multiplication factor of the outlet mass flow rate, so the respective partial differential is quite easy to obtain.

$$
\frac{\partial \dot{p}_{6}^{*}}{\partial \dot{m}_{\text {fuel }}}=0 ; \quad \frac{\partial \dot{p}_{6}^{*}}{\partial A_{8}}=-\frac{R_{g} T_{6}^{*} \dot{m}_{8}}{V_{D} A_{8}}
$$




\subsubsection{Partial derivatives of exhaust nozzle inlet total temperature}

The stagnation temperature upstream of the exhaust nozzle is described by Eq. (13), which is similar to the one about $T_{3}^{*}$ but it does not contain fuel injection and combustion. Therefore the deduction of the members will be slightly less complicated.

For the rotor speed, it is only found in the $q\left(\lambda_{3}\right)$ dimensionless mass flow rate inherited from the turbine inlet, consequently the partial derivative is quite simple.

$$
\frac{\partial \dot{T}_{6}^{*}}{\partial n}=\frac{R_{g} T_{6}^{*} \dot{m}_{6}}{m_{D} c_{v} q\left(\lambda_{3}\right)} \frac{K_{T}}{\sqrt{T_{3}^{*}}} C_{T}^{n}
$$

The $p_{3}{ }^{*}$ stagnation pressure at the turbine inlet is contained within the exhaust nozzle inlet mass flow rate and its $q\left(\lambda_{3}\right)$ dimensionless mass flow rate component is also depending on this variable.

$$
\frac{\partial \dot{T}_{6}^{*}}{\partial p_{3}^{*}}=\frac{R_{g} T_{6}^{*}}{m_{D} c_{v}}\left[\frac{\dot{m}_{6}}{p_{3}^{*}}+\frac{\dot{m}_{6}}{q\left(\lambda_{3}\right)} \frac{\sigma_{D}}{p_{6}^{*}} C_{T}^{p_{3}^{*}}\right]
$$

The turbine inlet total temperature $T_{3}{ }^{*}$ behaves similar to the previous pressure, but it is contained in the above mentioned locations as a square root in the denominator.

$$
\frac{\partial \dot{T}_{6}^{*}}{\partial T_{3}^{*}}=-\frac{R_{g} T_{6}^{*} \dot{m}_{6}}{2 m_{D} c_{v} T_{3}^{*}}\left[\frac{K_{T} n}{q\left(\lambda_{3}\right) \sqrt{T_{3}^{*}}} C_{T}^{n}+1\right]
$$

The exhaust nozzle inlet pressure is found in the dimensionless mass flow rate $q\left(\lambda_{3}\right)$ and in the outlet mass flow rate as shown in (58) and (59). In Eq. (66), the partial derivative of $q\left(\lambda_{8}\right)$ is not detailed due to its complexity, see Eq. (60).

$$
\begin{aligned}
& \frac{\partial \dot{T}_{6}^{*}}{\partial p_{6}^{*}}=-\frac{R_{g} T_{6}^{*}}{m_{D} c_{v}}\left[\frac{\dot{m}_{6}}{q\left(\lambda_{3}\right)} \frac{\sigma_{D} p_{3}^{*}}{p_{6}^{* 2}}\left(\frac{c_{1} K_{T} n}{\sqrt{T_{3}^{*}}}+c_{3}\right)+\right. \\
& \left.+\frac{\dot{m}_{8}}{p_{6}^{*}}+\frac{\dot{m}_{8}}{q\left(\lambda_{8}\right)} \frac{\partial q\left(\lambda_{8}\right)}{\partial p_{6}^{*}}\right]-\frac{R_{g} T_{6}^{*}\left(\dot{m}_{6}-\dot{m}_{8}\right)}{m_{D} c_{v} p_{6}^{*}}
\end{aligned}
$$

There is a single state variable remaining, the $T_{6}^{*}$ stagnation temperature, which has two locations where it appears in (13). These are the mass contained within the volume of the nozzle, which can be detailed according to the ideal gas law; and the outlet mass flow rate, whose formula has a square root of this temperature in its denominator. Therefore, taking these assumptions into account, the final partial derivative for a state variable can be expressed as shown in Eq. (67).

$$
\frac{\partial \dot{T}_{6}^{*}}{\partial \dot{m}_{\text {fuel }}}=0 ; \quad \frac{\partial \dot{T}_{6}^{*}}{\partial A_{8}}=-\frac{R_{g} T_{6}^{*} \dot{m}_{8}}{m_{D} c_{v} A_{8}}
$$

Equation (13) still includes some dependencies on input variables. When investigating the fuel mass flow rate, one can state, this variable is not contained in any form in Eq. (13), so the corresponding partial derivative will be equal to zero. The outflow cross sectional area $A_{8}$ is a factor in the formula of exhaust mass flow rate, i.e. it is resulting in a respective expression found in (68), which clearly identifies, that the stagnation temperature $T_{6}^{*}$ will decrease if the exhaust nozzle is opened; this corresponds the unloading of the turbojet engine, also detectable in the experiments.

$$
\frac{\partial \dot{T}_{6}^{*}}{\partial T_{6}^{*}}=\frac{2 R_{g}\left(\dot{m}_{6}-\dot{m}_{8}\right)}{m_{D} c_{v}}+\frac{R_{g} \dot{m}_{8}}{2 m_{D} c_{v}}
$$

\section{Conclusions}

In the present article, the authors have laid the basic formulation of the linear, time-invariant state-space model for a single-spool turbojet engine with special emphasis on the variable convergent nozzle.

Nevertheless, it has to be strongly underlined that the present state of the development is only a preliminary step in the whole process. The next stage of the investigation must contain the measurement-based identification of the system static and dynamic parameters, in order to fill the members of matrices with numeric information regarding the gas turbine engine. At this step, some members of the equation system can be proven as negligible; at the present stage such a sentence cannot be made. After one has determined the actual model describing the real system, verification must follow; then the main properties of the system should be investigated, like controllability, observability, stability. Following these steps, the effective work can take place on establishing a linear quadratic servo control in order to allow the system to track a reference signal determined by the user (e.g. pilot, etc.).

The aim of this article was to provide such a deep insight on the physical behaviour of the gas turbine engine, so that the established model might be the basis not only for control, but also for engine condition monitoring, in order to detect, isolate and accommodate faults, resulting in a fault tolerant system, which can be then further developed into an intelligent engine.

\section{Acknowledgment}

The work presented in this paper was supported by VEGA, Grant Agency of Ministry of Education and Academy of Science of Slovak Republic under Grant No.1/0776/17 - "Progressive algorithms in control, modeling and diagnostics of small jet engines".

This paper is supported by KEGA under Grant No. 014TUKE-4/2015 - "Digitalization, virtualization and testing of a small turbojet engine and its elements using stands for modern applied lecturing". This support is very gratefully acknowledged. 


\section{References}

Ailer, P., Sánta, I., Szederkényi, G., Hangos, K. M. (2001). Nonlinear Model-Building of a Low-Power Gas Turbine. Periodica Polytechnica Transportation Engineering. 29(1-2), pp. 117-135.

Andoga, R., Komjáty, M., Főző, L., Madarász, L. (2014). Design of the variable exhaust nozzle control system for a small turbojet engine MPM-20. In: 2014 IEEE 12th International Symposium on Applied Machine Intelligence and Informatics (SAMI), Herl'any, Jan. 23-25, 2014, pp. 195-199. https://doi.org/10.1109/SAMI.2014.6822405

Andoga, R., Főző, L., Madarász, L., Karol', T. (2013). A Digital Diagnostic System for a Small Turbojet Engine. Acta Polytechnica Hungarica. 10(4), pp. 45-58. https://doi.org/10.12700/APH.10.04.2013.4.3

Beneda, K. T. (2008). Kisméretü gázturbinás sugárhajtómüves berendezés kísérleti és oktatási célokra. (Small scale turbojet test bench for research and educational purposes). Repüléstudományi Közlemények. 20(1), pp. 117-132. (in Hungarian). [Online]. Available from: http://www. repulestudomany.hu/kulonszamok/2008_cikkek/Beneda_Karoly.pdf [Accessed: 17th May 2016]

Bicsák, Gy., Veress, Á. (2015). Verification of a Cost Efficient Solution to Simulate the Airflow Conditions in an Oil-To-Air Heat Exchanger of a Small Aircraft Applying Porous Material. Repüléstudományi Közlemények. 27(2), pp 253-271. [Online]. Available from: http://www.repulestudomany.hu/folyoirat/2015_2/2015-2-19-0209_Bicsak_Gyorgy-Veress_Arpad. pdf [Accessed: 17th May 2016]

Elkhateeb, N. A., Badr, R. I., Abouelsoud, A. A. (2014). Constrained Linear State Feedback Controller for a Low-Power Gas Turbine Model. Journal of Control Engineering and Technology. 4(1), pp. 66-75.

Garg, S. (1989). Turbofan Engine Control System Design Using the LQG/LTR Methodology. In: IEEE American Control Conference, Pittsburgh Hilton Hotel and Towers, Pittsburgh, PA, Jun. 21-23, 1989, pp. 134-141.

Hamza, A. M., Saad, M. S, Rashad, H. M., Bahgat, A. (2013). Gas Turbine LQR, INTEGRAL Controllers and Optimal PID Tuning by Ant Colony Optimization Comparative Study. International Journal of Computer Science and Telecommunications. 4(1), pp. 35-41.

Katolický, Z. Bušov, B., Bartlová, M. (2014). Turbojet engine innovation and TRIZ. In: $16^{\text {th }}$ International Conference on Mechatronic, 3-5 Dec. 2014, Brno, Czech Republik, pp. 16-23. https://doi.org/10.1109/MECHATRONIKA.2014.7018230

Kulikov, G. G., Thompson, H. A. (2004). Dynamic Modeling of Gas Turbines: Identification, Simulation, Condition Monitoring and Optimal Control. Springer Verlag, London, 2004.

Matsunuma, T., Yoshida, H., Iki, N., Ebara, T., Sodeoka, S., Inoue, T., Suzuki, M. (2005). Micro Gas Turbine with Ceramic Nozzle and Rotor. In: ASME Turbo Expo 2005: Power for Land, Sea, and Air. Reno, Nevada, USA, June 6-9, 2005. pp. 973-979. https://doi.org/10.1115/GT2005-68711

do Nascimento, M. A. R., de Oliveira Rodrigues, L., dos Santos, E. C., Gomes, E. E. B., Dias, F. L. G., Velásques, E. I. G., Carrillo, R. A. M. (2013). Micro Gas Turbine Engine: A Review. In: Progress in Gas Turbine Performance. (Benini, E. (ed.)) 2013. https://doi.org/10.5772/54444
Nagahara, M., Yamamoto, Y., Miyazaki, S., Kudoh, T., Hayashi, N. (2012). $\mathrm{H}_{\infty}$ Control of Microgrids Involving Gas Turbine Engines and Batteries. In: 2012 IEEEE $51^{\text {st }}$ Annual Conference on Decision and Control. Maul, Hawaii, USA, Dec. 10-12. 2012, pp. 4241-4246. https://doi.org/10.1109/CDC.2012.6427065

Pásztor, E., Beneda K. (2015). A TKT-1 kisméretű, oktatási és kutatási célú gázturbinás sugárhajtómű első tízéve. (First ten years of TKT-1 turbojet engine for research and education purposes). Repüléstudományi Közlemények. 27(3), pp. 117-132. (in Hungarian) [Online]. Available from: http://www.repulestudomany.hu/folyoirat/2015_3/2015-3-09-0238_ Pasztor_E-Beneda_K_T.pdf [Accessed: 17th May 2016]

Pečinka, J., Jílek, A. (2012).Preliminary Design of a Low-Cost Mobile Test Cell for Small Gas Turbine Engines. In: ASME Turbo Expo 2012: Turbine Technical Conference and Exposition. Vol. 3., Copenhagen, Denmark, Jun. 11-15, 2012. pp. 471-478.

https://doi.org/10.1115/GT2012-69419

Rohacs, J., Rohacs, D. (2012) Possible deployment of the UAV in commercial air transport. In: Proceedings of $6^{\text {th }}$ International UAV World Conference. (AIRTECH) Frankfurt am Main, Germany, Nov. 6 -8, 2012, CDROM. pp. 1-8.

Tavakolpour-Saleh, A. R., Nasib, S. A. R., Sepasyan, A., Hashemi, S. M. (2015). Parametric and nonparametric system identification of an experimental turbojet engine. Aerospace Science and Technology. 43, pp. 21-29. https://doi.org/ 10.1016/j.ast.2015.02.013

Tudosie, A. N. (2012). Aircraft single-spool single-jet engine with variable area exhaust nozzle. In: 2012 International Conference on Applied and Theoretical Electricity (ICATE), Craiova, Romania, Oct. 25-27, 2012, pp. 1-6. https://doi.org/10.1109/ICATE.2012.6403465

Turan, O. (2012). Exergetic effects of some design parameters on the small turbojet engine for unmanned air vehicle applications. Energy. 46(1), pp. 51-61. https://doi.org/10.1016/j.energy.2012.03.030

Verstraete, D., Hendrick, P., Djanali, V., Gonzales, C., Ling, J., Wong, K. C., Armfield, S. (2010). Micro propulsion activities at the University of Sydney. In: Proceedings of the PowerMEMS 2010 Conference. 2010, pp. 255-258. [Online] Available from: http://cap.ee.ic.ac.uk/ pdm97/powermems/2010/ poster-pdfs/255_Verstraete_41.pdf [Accessed: 17th May 2016]

Wiese, A. P., Blom, M. J., Manzie, C., Brear, M. J., Kitchener, A. (2015). Model reduction and MIMO model predictive control of gas turbine systems. Control Engineering Practice. 45, pp. 194-206. https://doi.org/ 10.1016/j.conengprac.2015.09.015

Williams, R. L., Lawrence, D. A. (2007). Linear State-Space Control Systems. John Wiley \& Sons, Hoboken, New Jersey, 2007.

Zare, F., Veress, Á. (2013). Mathematical Model Development and Thermodynamical Cycle Analyses of a Dual Spool no By-pass and a Dual Spool Mixed Turbofan Engines. In: International Conference on Innovative Technologies: IN-TECH 2013. Car, Z., Kudláček, J., Szalay, T. (Eds.)) pp. 41-44. 